\title{
El Saqueo del Museo de Irak
}

Ernesto Cardenal ${ }^{1}$

Recibido: 17 de abril de 2012 / Aprobado: 18 de abril de 2012.

Yo estuve en este museo

fue antes de Saddam Ussein

y pensé hacer un poema

por ser el unico museo del mundo

que era de toda la humanidad

desde cazadores-recolectores hasta hoy

y me traje un catálogo que aún tengo

el único museo de la evolución humana que acaba

de ser saqueado

y no existe más

Recorrámoslo en la imaginación la primera pieza era una piedra apenas un poquito labrada esqueletos del Neanderthal que aqui hubo y el hombre de las cavernas cazadores-recolectores que domesticaron animales sembraron cebada trigo lentejas arado primitivo y las primeras ruedas (en el catálogo)

la obesa belleza de diosas-madres:

nalgas pechosy

el primer metal labrado

los primeros templos

La historia empieza con los sumerios la primera civilización del mundo los

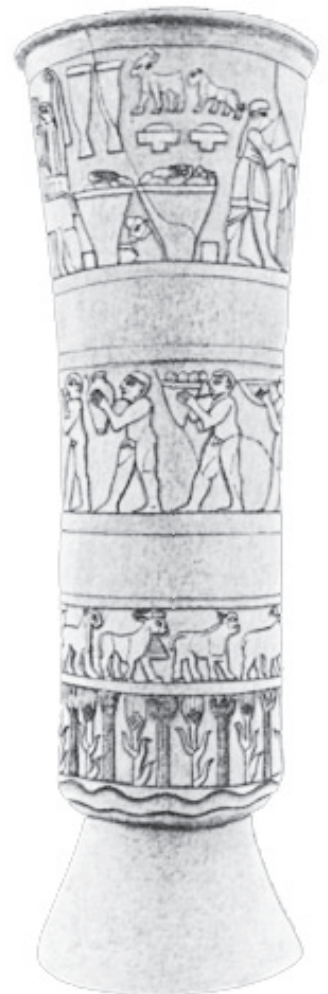

egiptologia.com misteriosos sumerios no se sabe de dónde vinieron su antiquisimos mitos llegaron hasta la Biblia y -ya ahora palabra verdadera de Dios- hasta nosotros

la primera cultura que conocemos

Irak como cuna de la civilización cuna de la escritura y de las ciudades las matemáticas la medicina la astronomía el comercio abogados carpinteros joyeros impuestos sobre la renta fuerzas armadas

Europa aún en tinieblas son 100.000 años de la especie humana y sólo 10.000 son de civilización que empezó en Mesopotamia donde hubo el primer código legal y por primera vez se estudiaron las estrellas donde hubo la primera escritura del mundo

que después fue cuneiforme y pronto trasmitida a la otra segunda gran potencia la del Nilo

La primera escritura fueron dibujos alguien vio que podía pintar en lodo el lodo que allí abunda (lodo con el que inventaron el adobe que aún usamos)

1 Poeta, sacerdote, teólogo, escritor, traductor, escultor y político. (Nicaragua) 


\section{Literatura}

$y$ asi los textos más antiguos del mundo están en barro el escriba embrocado sobre su tableta de barro apuntando el ciclo la mina y el talento el parto de las ovejas y el movimiento de los astros miles y miles de tabletas el escribir se volvió mania

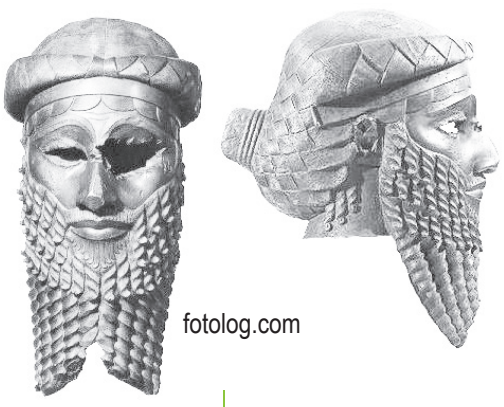
barro metal hueso madera vidrio alabastro desde la prehistoria a nuestros dias de alfabetización en TV y computadora en árabe desde la joyería de oro de los sumerios

(lira de oro puro con ciervos asustados) hasta la cristaleria y manuscritos persas documentos de la historia de los pueblos estados imperios civilizaciones el colegial puede enumerarlos sumerios acadios babilonios asirios persas griegos partos judios árabes destruidos 10.000 años de historia y un siglo de investigación y la inundación que está en la Biblia $Y$ el primer rostro humano en el arte ("en Irak de todo se puede decir primero") el primer legislador abolida la ley del talión

2.000 años antes de Cristo

y que "el fuerte no oprima al débil ni el huérfano presa del rico en la dura diorita o en barro: "proteger viudas y huérfanos" también cómo tratarse unos a otros "aborrecian la mentira y la opresión"

Pero no sólo la historia de Irak 60.000 años de historia de la humanidad fueron saqueados las galerías del museo quedaron vacias el Pentágono prometió protegerlo Herramientas del inicio de la agricultura la primera alfarería (fea y hecha a mano)

las lineas sutiles de los sellos cilindricos todo amorosamente consignado en el catálogo

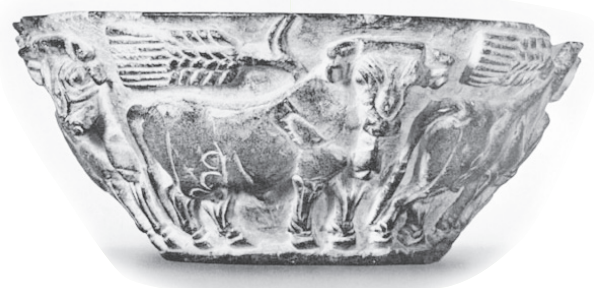

http://oi.uchicago.edu/OI/IRAQ/dbfiles/objects/16.htm
Los arqueólogos habian alertado al Pentágono Estados Unidos pudo detener el saqueo tres dias de pillaje según dicen

los marines estaban a 100 varas

y miraban inmóviles

(Es una exageración

dijo a los periodistas el Secretario de Defensa) pero si protegieron el Ministerio del Petróleo la Biblioteca Nacional ardiendo por dos dias fue para humillar a Irak y someterlo a Estados Unidos y sus titeres en Bagdad como el saqueo de Bagdad por los mongoles una agresión a la identidad nacional y a 7.000 años de historia cultural estante por estante fueron tirados al suelo estatuas ánforas jarrones asirios babilonios sumerios persas griegos el plinto de mármol de 5.000 años que sobrevivieron a los sitios de Bagdad pero no a la "liberación" de Bush 


\section{Literatura}

60.000 años de historia de la humanidad

no habia tiempo de ver todo el museo

que ya no se verá

14.000 objetos que ya no están o están destruidos pisoteados en el suelo todo por el petróleo

"Miren" (un trozo de cerámica) "esto era asirio"

la única colección completa de la historia humana

y se perdió por los marines

piezas tan valiosas que ninguna

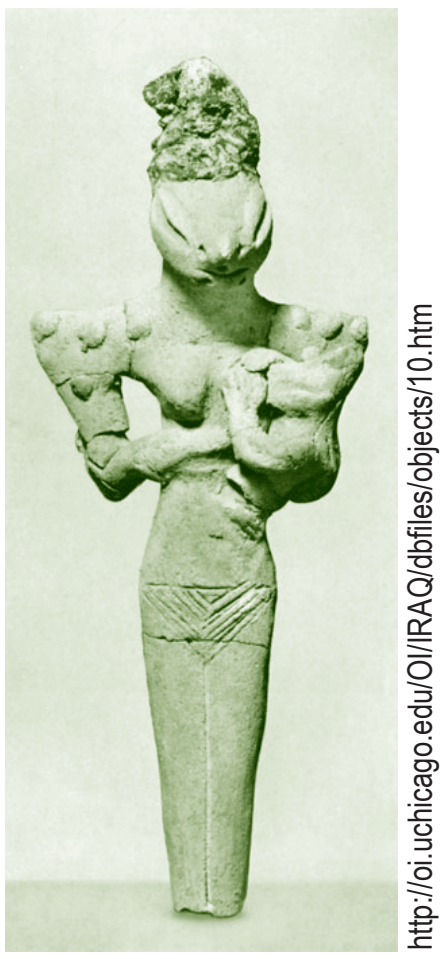

compañia de seguros aseguraba cargados en autos y camiones lo saqueado a la vista de las tropas de Estados Unidos

ahora tal vez en tiendas de anticuarios tal vez comprados como regalos de Navidad suvenires y objetos de decoración o demasiado conocidos para aparecer en subastas pero puestos en garantía en tratos de drogas

o escondidos en cajas fuertes de algún banco y ya no se verán.

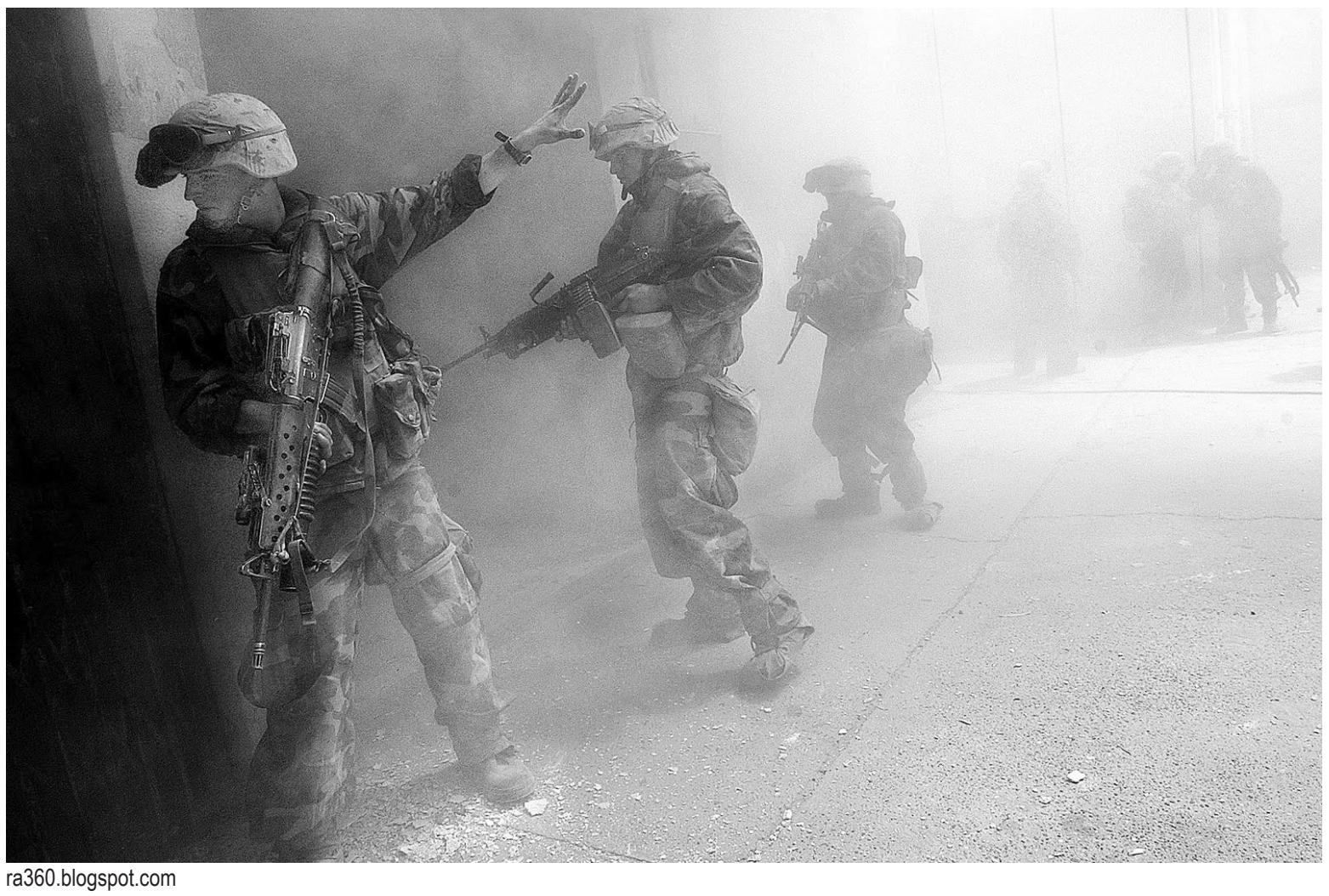

